\title{
Aortic arch reconstruction using a Kommerell diverticulum for hypoplastic left heart syndrome with a right aortic arch
}

\author{
Shunsuke Matsushima, MD, Yoshihiro Oshima, MD, PhD, and Hironori Matsuhisa, MD, PhD, Kobe, Japan
}

\author{
From the Department of Cardiovascular Surgery, Kobe Children's Hospital, Kobe, Japan. \\ Disclosures: Authors have nothing to disclose with regard to commercial support. \\ Received for publication Jan 3, 2016; revisions received Jan 20, 2016; accepted for publication Jan 27, 2016; \\ available ahead of print March 30, 2016. \\ Address for reprints: Shunsuke Matsushima, MD, Department of Cardiovascular Surgery, Kobe Children's \\ Hospital, 1-1-1, Takakuradai, Suma-ku, Kobe 654-0081, Japan (E-mail: matsushima_kch@hp.pref.hyogo.jp). \\ J Thorac Cardiovasc Surg 2016;152:e35-7 \\ $0022-5223 / \$ 36.00$ \\ Copyright (c) 2016 by The American Association for Thoracic Surgery \\ http://dx.doi.org/10.1016/j.jtcvs.2016.01.057
}

We describe right aortic arch reconstruction using a Kommerell diverticulum in a Norwood modification for hypoplastic left heart syndrome (HLHS) with a hypoplastic right aortic arch, a Kommerell diverticulum, and a right-sided descending aorta. This method removes the retroesophageal component of the aorta and ensures an unobstructed aortic pathway and a sufficient aortopulmonary space with the advantage of growth potential.

\section{CLINICAL SUMMARY}

A $2.41-\mathrm{kg}$ female neonate was born at 36 weeks gestation with a prenatal diagnosis of HLHS that required prostaglandin E1 infusion. Transthoracic echocardiography confirmed the diagnosis of HLHS, mitral stenosis aortic atresia subtype, with right aortic arch, aberrant left subclavian artery, left ductus arteriosus, and bilateral superior vena cava. Bilateral pulmonary artery banding was performed on postnatal day 3. Computed tomography (CT) performed on postnatal day 29 revealed a hypoplastic right aortic arch, a large-diameter Kommerell diverticulum, and a right-sided descending aorta along with the aforementioned aortic arch morphology (Figure 1, A).

The modified Norwood operation was performed at age 48 days, when the patient weighed $3.27 \mathrm{~kg}$. After a median sternotomy, an arterial cannula was inserted through a 3-mm expanded polytetrafluoroethylene tube (GoreTex; WL Gore, Flagstaff, Ariz) sewn onto the left common carotid artery. Bicaval venous drainage was achieved, and cardiopulmonary bypass, with mild hypothermia $\left(32^{\circ} \mathrm{C}\right)$, was initiated. A second arterial cannula was placed in the descending aorta just above the diaphragm.

Once the aberrant left subclavian artery and ductus arteriosus were divided, the Kommerell diverticulum and ductus arteriosus were mobilized to the right side of the trachea (Figure 2, A). The thick-walled fragile ductal tissue was completely excised until the normal thin wall of the Kommerell diverticulum appeared, and a glutaraldehydetreated autologous pericardial (GA-AP) patch was sutured to the inferior wall of the Kommerell diverticulum to aortic arch. ${ }^{1}$ complications.

\section{DISCUSSION}

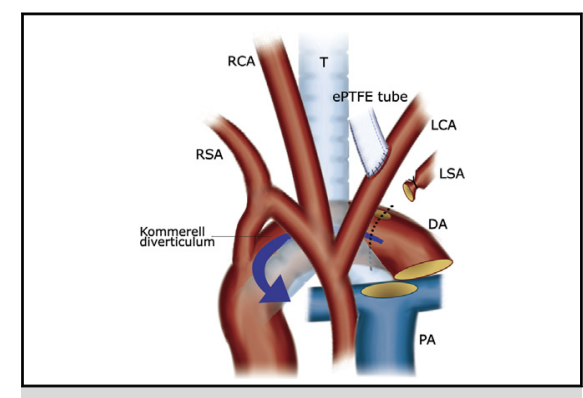

Norwood modification using a Kommerell diverticulum for HLHS with a right aortic arch.

Central Message

We describe a report of successful right aortic arch reconstruction using a Kommerell diverticulum for HLHS with a right aortic arch.

See Editorial Commentary page e39.

augment the lesser curvature of the newly reconstructed

On cardiac arrest, the transected ascending aorta was anastomosed side-by-side to the transected main pulmonary artery, and this amalgamation was joined to the Kommerell diverticulum with the GA-AP patch (Figure 2, B). After the distal end of the right aortic arch was divided and the superior wall of the Kommerell diverticulum was opened longitudinally, this continuity from the neoaortic root to the descending aorta was anastomosed to the longitudinally opened aortic arch (Figure 2,C). Atrial septectomy and right ventricle to pulmonary artery shunt placement, using a 6-mm GoreTex tube, were performed as well. The patient was weaned from cardiopulmonary bypass without any

The patient's postoperative course was uneventful. She was extubated on postoperative day 10 and showed no respiratory symptoms. Neither aortic recoarctation nor airway compression was evident on postoperative CT (Figure 1,B). A bilateral bidirectional Glenn shunt was performed when the patient was 5 month old. At the 2-month follow-up after surgery, the patient's condition was stable, and she was waiting for a Fontan procedure.

Right aortic arch hypoplasia in a variant of HLHS is extremely rare. Few reports have described the operative technique of the Norwood procedure in this patient 

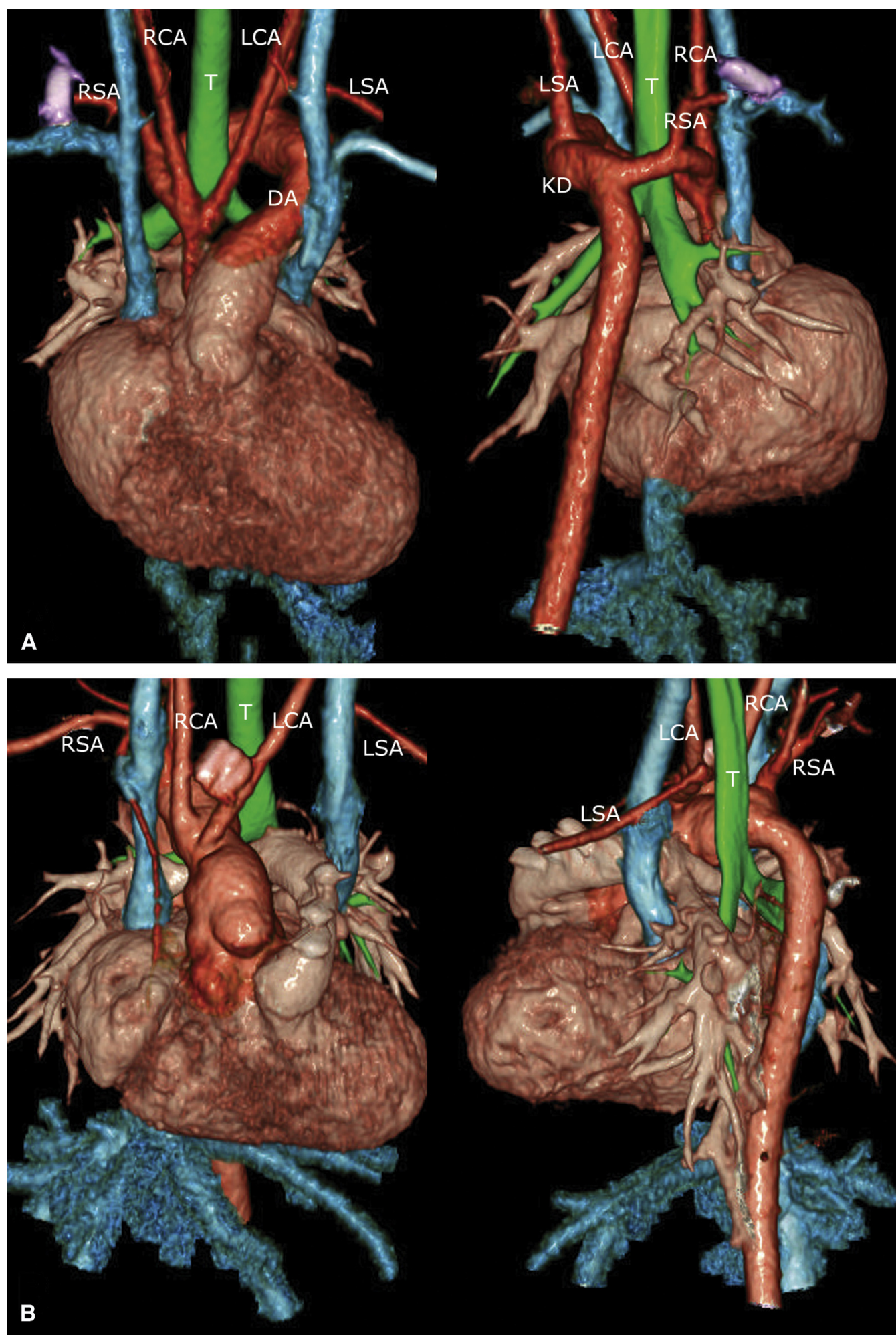

FIGURE 1. (A) Serial multidetector CT images obtained after bilateral pulomary artery banding revealing a vascular ring composed of a hypoplastic right aortic arch, a left ductus arteriosus $(D A)$, and a Kommerell diverticulum $(K D)$. (B) Images obtained after the Norwood procedure. The new right aortic arch was reconstructed without aortic obstruction and had a sufficient aortopulmonary space. $L C A$, Left carotid artery; $L S A$, left subclavian artery; RCA, right carotid artery; $R S A$, right subclavian artery; $T$, trachea. 

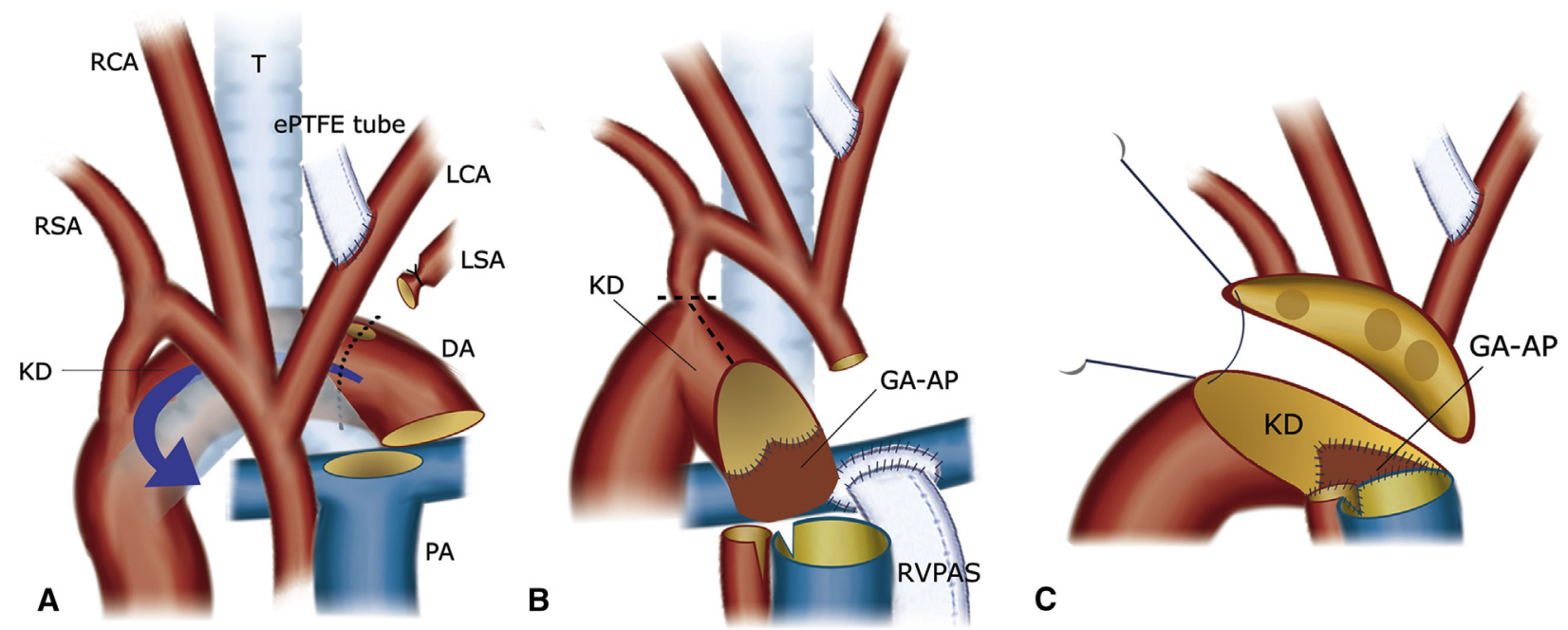

FIGURE 2. Schematic diagram of the Norwood procedure. (A) The Kommerell diverticulum $(K D)$ and ductus arteriosus $(D A)$ were mobilized to the right side of the trachea (blue arrow), and the ductal tissue was completely excised (dotted line). (B) The neoaortic root was joined to the Kommerell diverticulum with the glutaraldehyde-treated autologous pericardial $(G A-A P)$ patch, followed by opening the superior wall of the Kommerell diverticulum longitudinally (dashed line). (C) This continuity from the neoaortic root to the descending aorta was anastomosed to the longitudinally opened aortic arch. ePTFE, Expanded polytetrafluoroethylene; $L C A$, left carotid artery; $L S A$, left subclavian artery; $P A$, pulmonary artery; $R C A$, right carotid artery; $R S A$, right subclavian artery; RVPAS, right ventricle to pulmonary artery shunt; $T$, trachea.

subtype. $^{2-4}$ All of these cases involved an aberrant innominate or subclavian artery and a left-sided proximal descending aorta. Two of these patients underwent patch augmentation of the aortic arch and left the aortic pathway behind the esophagus, ${ }^{2,3}$ and the other patient had a new aortic arch reconstructed in front of the trachea with a homograft patch. ${ }^{4}$

The important consideration in this population of patients is surgical management for the retroesophageal component of the aorta after vascular ring division. The remaining retroesophageal aorta or the circumflex aorta often cause airway or esophagus obstruction and should be removed. ${ }^{3,5}$ Therefore, the side of aortic arch reconstruction should be determined depending on the position of the proximal descending thoracic aorta. In this case, we decided to reconstruct the right aortic arch and to pull the Kommerell diverticulum away from the midline behind the esophagus.

Another issue involves the type of material used for augmentation of the newly reconstructed aortic arch. This type of aortic arch reconstruction often requires a large patch because of a shortage of the aortic wall and the long distance between the pulmonary artery and the descending aorta. ${ }^{4}$ In addition to the arch angle augmentation with GA-AP, which our group reported previously, ${ }^{1}$ the Kommerell diverticulum was incorporated into this neoaortic arch to create an unobstructed aortic pathway and enlarge the aortopulmonary space. This use of the Kommerell diverticulum is expected to contribute to growth of the neoaorta.

The Norwood operation for HLHS with a right aortic arch can be challenging. Our current experience is limited, but nonetheless may provide valuable information for other congenital cardiac surgeons.

\section{References}

1. Hasegawa T, Oshima Y, Maruo A, Matsuhisa H, Tanaka A, Noda R, et al. Aortic arch geometry after the Norwood procedure: the value of arch angle augmentation. J Thorac Cardiovasc Surg. 2015;150:358-66.

2. Sett SS, Mawson JB, Sandor GGS. Repair in infancy of right aortic arch with aberrant left brachiocephalic artery in the setting of a variant of the hypoplastic left heart syndrome. Cardiol Young. 2004;14:441-3.

3. Tatum GH, Morell VO, Park SC. The management of hypoplastic left heart syndrome with a right aortic arch. Cardiol Young. 2006;16:504-6.

4. Patel PM, Bartlett HL, Scholz T, Burzynski J, Behrendt DM, Burkhart HM Norwood modification in a patient with hypoplastic left heart and a right aortic arch. J Thorac Cardiovasc Surg. 2007;134:1065-6.

5. Backer CL, Mongé MC, Russell HM, Popescu AR, Rastatter JC, Costello JM Reoperation after vascular ring repair. Semin Thorac Cardiovasc Surg Pediatr Card Surg Annu. 2014;17:48-55. 